Christine Lamarre, Claude Farenc (éd.), Émeutes et journées révolutionnaires en Côte-d'Or, 1775-1800

\title{
Samuel Guicheteau
}

\section{Q OpenEdition \\ 1 Journals}

Édition électronique

URL : https://journals.openedition.org/ahrf/12078

DOI : 10.4000/ahrf.12078

ISSN : 1952-403X

\section{Éditeur :}

Armand Colin, Société des études robespierristes

\section{Édition imprimée}

Date de publication : 1 juin 2011

Pagination : 270-271

ISSN : 0003-4436

\section{Référence électronique}

Samuel Guicheteau, « Christine Lamarre, Claude Farenc (éd.), Émeutes et journées révolutionnaires en Côte-d'Or, 1775-1800 », Annales historiques de la Révolution française [En ligne], 364 | avril-juin 2011, mis en ligne le 31 août 2011, consulté le 23 avril 2022. URL : http://journals.openedition.org/ahrf/12078 ; DOl : https://doi.org/10.4000/ahrf.12078

Ce document a été généré automatiquement le 23 avril 2022.

Tous droits réservés 


\title{
Christine Lamarre, Claude Farenc (éd.), Émeutes et journées
} révolutionnaires en Côte-d'Or, 1775-1800

\author{
Samuel Guicheteau
}

\section{RÉFÉRENCE}

Christine Lamarre, Claude Farenc, éd., Émeutes et journées révolutionnaires en Côte-d'Or, 1775-1800, actes de la journée d'études du 25 novembre 2005, Dijon, Archives départementales de la Côte-d'Or, Cahier du Comité départemental pour l'histoire de la Révolution en Côte-d'Or, nouvelle série $\mathrm{n}^{\circ}$ 2, 2009, 176 p.

1 Bienheureux département de la Côte-d'Or qui bénéficie non seulement d'une solide tradition d'études révolutionnaires mais encore aujourd'hui d'un actif Comité d'histoire de la Révolution française! Après un volume consacré aux réjouissances civiques, celui-ci publie donc les actes d'une journée d'études consacrée aux émeutes et journées révolutionnaires. Dans son introduction, C. Lamarre mobilise de nombreuses références historiographiques provinciales (depuis l'érudition locale du $\mathrm{XIX}^{\mathrm{e}}$ siècle jusqu'aux recherches de M. Edelstein en passant par les ouvrages de P. de Saint-Jacob, de J.Bart et tant d'autres) tout en replaçant les études ici rassemblées dans des perspectives de recherches plus larges (depuis la querelle entre B.Porchnev et R. Mousnier jusqu'à l'enquête de J. Nicolas sur La rébellion française en passant par les débats du Bicentenaire). En remontant à l'émeute frumentaire qui éclate à Dijon le 18 avril 1775 et annonce la Guerre des Farines (S. Pannekoucke), en donnant des éclairages sur les diverses étapes de la Révolution (mais la période 1793-94 reste un peu occultée), en n'ignorant pas les années 1800 (par exemple pour l'étude des tumultes au théâtre de Dijon), mais surtout en offrant un kaléidoscope de conflits, cet ouvrage enrichit notre connaissance des tensions révolutionnaires, de leurs enjeux et de leurs acteurs. 
Ce volume aborde des enjeux sociaux tels que le problème des subsistances ou la question de l'accès à la terre qui met en compétition villageois et propriétaires à Géanges (J. Sirdey) comme à La Bussière-sur-Ouche (J. Bart). Sur le plan politique, sont examinés les réformes de Turgot et les oppositions qu'elles suscitent, la nouvelle compétition électorale, le contrôle de la garde nationale (G. Lévêque) et encore le découpage départemental et les divers enjeux qu'il recèle. Sur le plan culturel, différentes contributions abordent la question religieuse (de l'anticléricalisme des Lumières à l'agitation attisée par les réfractaires), la mutation de l'éducation et les résistances auxquelles elle se heurte ( $\mathrm{S}$. Morlot), le répertoire théâtral et sa censure (C. Trehorel). Ces multiples enjeux mobilisent des acteurs très variés. À l'étude des mobilisations du peuple des villes et de celui des champs répond celle des élites, aristocrates ébranlés mais pas résignés à l'instar de ceux de Beaune (S. Dollinger), ou bien bourgeois affirmant leurs prétentions nouvelles tant politiques qu'économiques. L'examen des tensions religieuses passe tant par l'étude de l'avidité des moines de Cîteaux (F. Seichepine) que par celle des résistances des fidèles, en particulier les femmes, paroissiennes attachées aux prêtres réfractaires, ou encore jeunes filles de l'hospice de Dijon récalcitrantes à l'arrivée d'éducatrices acquises aux principes révolutionnaires. Sur le plan militaire, à l'analyse d'une mutinerie menée en 1790 par des soldats probablement mus par une hostilité sociale contre leurs officiers au sang bleu (R. David) fait écho l'intérêt porté aux insoumis sous le Directoire (C. Farenc). Enfin, des pratiques diverses sont mises en œuvre par ces différents acteurs suivant les scènes et les enjeux des affrontements : lutte électorale, cris séditieux, charivari, voire meurtre.

3 Au total, une chronologie des tensions départementales s'esquisse, qui s'inscrit dans la dynamique révolutionnaire générale: Grande peur de 1789, tensions entre patriotes modérés et avancés en 1791 (par exemple à Vitteaux), emprisonnement de nombreux suspects en 1792, affrontement entre républicains et royalistes sous le Directoire. Mais alors réapparaît la question de l'an II dans ce département «bleu» (C. Lamarre). L'action vigoureuse des représentants en mission et des sans-culottes locaux, organisés en sociétés populaires et comités de surveillance, a en fait contenu les tensions, sans les faire disparaître. Peut-être l'approche géographique plus fine du département, que C. Lamarre appelle de ses vœux, apporterait-elle un éclairage complémentaire. Pour l'instant, cet ouvrage intéressera tous ceux que passionne la Révolution. 